\title{
ANALISIS PENYEBARAN LASA (Castanopsis buruana Miq) SEBAGAI POHON PENGHASIL PANGAN ALTERNATIF DI SERAM BAGIAN BARAT MALUKU
}

\section{DISTRIBUTION ANALYSIS OF LASA (Castanopsis buruana Miq) AS AN ALTERNATIVE FOOD-TREE IN THE WEST SERAM MOLUCCAS}

\author{
Irwanto $^{1)}$, Andri Tuhumury ${ }^{2)}$, Andjela Sahupala ${ }^{3)}$ \\ Jurusan Kehutanan Fakultas Pertanian Universitas Pattimura Ambon \\ Jl. Ir. M. Putuhena, Kampus Poka Ambon 97237 \\ Email : irwantoshut@gmail.com

\begin{tabular}{|l|l}
\hline Diterima: 10 Juni 2018 & Disetujui: 18 Juni 2018 \\
\hline
\end{tabular}

\begin{abstract}
Abstrak
Penelitian ini bertujuan untuk mengetahui penyebaran Lasa (Castanopsis buruana Miq) dan pemanfaatannya sebagai bahan makanan alternatif oleh masyarakat Seram Bagian Barat Provinsi Maluku. Analisis penyebaran Lasa (Castanopsis buruana Miq) dipergunakan metode petak tunggal pada berbagai ketinggian tempat dengan ukuran petak 200 x 200 meter. Dalam petak tunggal ini dibuat sub-sub petak dengan ukuran sesuai tingkat pertumbuhan. Hasil penelitian menunjukan penyebaran pohon Lasa (Castanopsis buruana Miq) berada pada ketinggian di atas $300 \mathrm{mdpl}$. Potensi penyebaran pada ketinggian 300, 400, $500 \mathrm{mdpl}$ di Desa Hunitetu adalah sebagai berikut 120 pohon/ha, 135 pohon/ha, dan 130 pohon/ha sedangkan Desa Murnaten sebesar 105 pohon/ha, 130 pohon/ha, dan 135 pohon/ha. Indeks Morisita menunjukkan Lasa (Castanopsis buruana Miq) memiliki pola sebaran mengelompok (clumped) dengan struktur populasi bentuk kurva "J" terbalik atau memiliki jumlah individu paling banyak pada tingkat permudaan. Masyarakat Desa Hunitetu memanfaatkan biji Lasa (Castanopsis buruana Miq) sebagai cemilan dan snack serta diolah menjadi pengganti beras, dimasak dengan air sebagai nasi atau dimasak dengan santan sebagai bubur.
\end{abstract}

Kata kunci : Lasa (Castanopsis buruana Miq), Analisis Penyebaran, dan Pangan Alternatif

\begin{abstract}
This research aims to observe the distribution of Lasa (Castanopsis buruana Miq) and its use as an alternative food ingredient by The West Seram community in Maluku Province. Analysis of the distribution of Lasa (Castanopsis buruana Miq) used a single plot method at various altitudes with a plot size of $200 \times 200$ meters. In this single plot, sub-plots were made according to the growth stages. The results showed that the distribution of Lasa tree (Castanopsis buruana Miq) was at an altitude above 300 meters above sea level. Potential spread at an altitude of 300 , 400, 500 masl in Hunitetu Village is as follows 120 trees / ha, 135 trees / ha, and 130 trees / ha while in Murnaten Village is 105 trees / ha, 130 trees / ha, and 135 trees / ha. The Morisita index shows that Lasa (Castanopsis buruana Miq) has a clumped distribution pattern with an inverted "J" curve population structure or has the most number in the regeneration stages. The Hunitetu village community uses seeds of Lasa (Castanopsis buruana Miq) as snacks or extra food and were processed into rice substitutes, cooked with water as rice or cooked with coconut milk as porridge.
\end{abstract}

Keywords: Lasa (Castanopsis buruana Miq), Distribution Analysis, and Alternative Food 


\section{PENDAHULUAN}

Ketahanan pangan nasional Indonesia menghadapi banyak tantangan baik dari dalam maupun dari luar. Salah satu dimensi terbaru adalah perubahan iklim dan cuaca ekstrem akibat pemanasan global yang tidak terduga langsung berdampak pada ketahanan pangan nasional. Pemanasan global menimbulkan perubahan iklim dan cuaca ekstrem. Iklim dan cuaca menjadi serba tidak pasti dan kadang berubah drastis tidak lagi mengikuti ritme iklim tropis dua musim penghujan dan musim kering, melainkan dalam ritme tumpang-tindih keduanya, hujan di musim kering, atau kering di musim hujan (Kusumasari, B., 2015; Perdana dan Susilowati, 2015).

Hutan di Indonesia sebagian besar digolongkan dalam hutan hujan tropis yang mempunyai keanekaragaman hayati yang tinggi. Banyak jenis tumbuh-tumbuhan di dalamnya belum dikaji secara detail manfaat dan kegunaannya untuk kesejahteraan manusia. Hutan merupakan ekosistem yang lebih stabil dibandingkan dengan ekosistem lain dimuka bumi ini selain penghasil oksigen yang disebut paru-paru dunia, hutan juga penghasil bahan makanan. Sejak dulu manusia mengambil manfaat dari hutan yang menghasilkan berbagai kebutuhan primer seperti sandang pangan dan papan. Masyarakat di sekitar hutan memungut dan mengolah produk hasil hutan non kayu yang sudah tersedia secara alami (Puspitojati. dkk, 2014).

\section{Lasa (Castanopsis buruana}

Miq) sebagai tumbuhan serbaguna yang dipergunakan untuk obat-obatan dan pangan alternatif namun belum diketahui potensi dan penyebarannya di alam khususnya di daerah Maluku. Penelitian ini bertujuan untuk mengetahui penyebaran Lasa (Castanopsis buruana Miq) di Seram Bagian Barat, dan mengetahui pemanfaatannya sebagai bahan makanan alternatif oleh masyarakat sekitar

\section{METODE PENELITIAN}

\section{Lokasi dan Waktu Penelitian}

Lokasi Penelitian adalah Kawasan Hutan Seram Bagian Barat pada tiga lokasi yaitu : Desa Hatusua, Desa Hunitetu dan Desa Murnaten. Penelitian lapangan dilaksanakan selama 1 (satu) bulan, yaitu pada bulan Mei 2017. 
Metode Pengumpulan Data

Metode

penelitian

menggunakan metode deskriptif

kuantitatif dan deskripsi kualitatif.

Data-data yang dikumpulkan adalah data primer. Data primer adalah datadata yang diambil langsung dari lapangan, baik berupa data studi potensi dan penyebaran Lasa (Castanopsis buruana Miq) maupun data hasil wawancara dengan masyarakat memakai panduan kuesioner.

Metode analisis penyebaran Lasa (Castanopsis buruana Miq) menggunakan metode petak tunggal yang dibuat pada berbagai ketinggian (altitude) yaitu 300, 400 dan 500 mdpl, dengan ukuran petak 200 x 200 meter. Dalam petak tunggal ini dibuat lagi sub-sub petak dengan ukuran sesuai tingkat pertumbuhan. Luas subpetak ukur untuk masing-masing tingkat pertumbuhan adalah sebagai berikut :

- Semai (seedlings) petak 2 × 2 m, yaitu sejak perkecambahan sampai tinggi 1,5 m;

- Sapihan (saplings) petak 5 x $5 \mathrm{~m}$, permudaan yang mencapai tinggi antara 1,5 meter dengan diameter batang kurang dari $10 \mathrm{~cm}$.
- Tiang (poles) petak 10 x $10 \mathrm{~m}$, tingkat pertumbuhan pohon muda berukuran dengan diameter batang antara $10-19 \mathrm{~cm}(\mathrm{dbh})$

- Pohon (trees) petak 20 x $20 \mathrm{~m}$, berdiameter batang diatas $20 \mathrm{~cm}$ (dbh)

\section{Metode Analisis Data}

Data vegetasi yang terkumpul kemudian dianalisis untuk mengetahui kerapatan jenis, kerapatan relatif, dominansi jenis, dominansi relatif, frekuensi jenis dan frekuensi relatif serta Indeks Nilai Penting menggunakan rumus Mueller-Dombois dan Ellenberg (1974) sebagai berikut:

$$
\begin{aligned}
& \text { Kerapatan } \\
& =\frac{\text { Jumlah Individu }}{\text { Luas Petak Ukur }} \\
& \text { Kerapatan Relatif } \\
& =\frac{\text { Kerapatan Satu Jenis }}{\text { Kerapatan Seluruh Jenis }} \times 100 \% \text {....2) } \\
& \text { Dominansi } \\
& =\frac{\text { Luas Penutupan Suatu Jenis }}{\text { Luas Petak }} \\
& \text { Dominansi Relatif } \\
& =\frac{\text { Dominansi Suatu Jenis }}{\text { Dominansi Seluruh Jenis }} \times 100 \% \text {... 4) } \\
& \text { Frekuensi }
\end{aligned}
$$

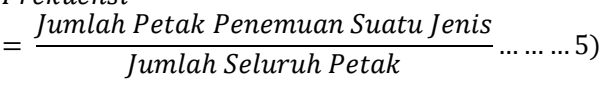

$$
\begin{aligned}
& \text { Frekuensi Relatif } \\
& =\frac{\text { Frekuensi Suatu Jenis }}{\text { Frekuensi Seluruh Jenis }} \times 100 \% \text {...6) }
\end{aligned}
$$

Nilai Penting = Kerapatan Relatif + Frekuensi

Relatif + Dominansi Relatif ....7) 
Nilai Penting adalah penjumlahan dari KR, FR dan DR, berkisar antara 0 dan 300. Untuk tingkat pertumbuhan sapihan dan semai merupakan penjumlahan KR dan FR, sehingga maksimum nilai penting adalah 200 .

Pola sebaran Lasa (Castanopsis buruana Miq) dihitung dengan menggunakan Indeks Morisita Terstandar (Morisita, 1959). Indeks tersebut dihitung dengan persamaan :

$$
I_{d}=n\left[\frac{\sum x^{2}-\sum x}{\left(\sum x\right)^{2}-\sum x}\right]
$$

Keterangan :

$\mathrm{I}_{\mathrm{d}}=$ Indeks Morisita

$\mathrm{n}=$ Jumlah plot

$\mathrm{x}=$ Jumlah individu yang ditemukan di setiap plot

Uniform Indeks $=M_{u}$

$$
=\frac{\chi_{0.975}^{2}-n+\sum x_{i}}{\left(\sum x_{i}\right)-1}
$$

Clumped Indeks $=M_{c}$

Keterangan :

$$
=\frac{\chi_{0.025}^{2}-n+\sum x_{i}}{\left(\sum x_{i}\right)-1}
$$

$\chi_{0.975}^{2}=$ Nilai tabel dengan df (n-1) yg memiliki $97,5 \%$ area ke sebelah kanan kurva

$\chi_{0.025}^{2}=$ Nilai tabel dengan df (n-1) yg memiliki 2,5\% area ke sebelah kanar(Castanopsis buruana Miq) baik di kurva

$\Sigma \mathrm{Xi}=$ Jumlah individu dalam plot

$\mathrm{n}=$ Jumlah plot

Berdasarkan hasil nilai $\mathrm{M}_{\mathrm{c}}$ atau $\mathrm{M}_{\mathrm{u}}$, maka Indeks Morisita Terstandar
Hasil

analisis vegetasi menunjukkan bahwa Lasa

dihitung berdasarkan salah satu dari empat kondisi berikut :

a. Jika $\mathrm{I}_{\mathrm{d}} \geq \mathrm{M}_{\mathrm{c}}>1=I_{p}=0,5+$ $0,5\left(\frac{I_{d}-M_{c}}{n-M_{c}}\right)$

b. Jika $\mathrm{M}_{\mathrm{c}}>\mathrm{I}_{\mathrm{d}} \geq 0=I_{p}=0,5+$ $0,5\left(\frac{I_{d}-1}{M_{u}-1}\right)$

c. Jika $1>\mathrm{I}_{\mathrm{d}}>\mathrm{M}_{\mathrm{u}}=I_{p}=0,5+$ $0,5\left(\frac{I_{d}-1}{M_{u}-1}\right)$

d. Jika $\mathrm{I}_{\mathrm{d}} \geq \mathrm{M}_{\mathrm{u}}>\mathrm{I}_{\mathrm{d}}=I_{p}=0,5+$ $0,5\left(\frac{I_{d}-M_{u}}{M_{u}}\right)$

Indeks Morisita yang distandarkan $\left(I_{p}\right)$ berkisar antara -1 hingga 1. Jika $I_{p}=0$, maka pola penyebaran adalah acak. Jika $\mathrm{I}_{\mathrm{p}}<0$, maka pola penyebaran adalah seragam; dan jika $I_{p}>0$, maka pola penyebarannya adalah mengelompok.

\section{HASIL DAN PEMBAHASAN}

Potensi Lasa (Castanopsis buruana Miq)

Desa Hunitetu maupun Desa Murnaten merupakan jenis dengan nilai kerapatan paling tinggi dibandingkan dengan jenis-jenis lainnya pada seluruh tingkat pertumbuhan. Sedangkan di Desa Hatusua tidak 
terdapat jenis ini karena mempunyai ketinggian tempat di bawah 300 mdpl.

Penyebaran Lasa (Castanopsis buruana Miq) pada Desa Hunitetu dan Murnaten memiliki kerapatan tinggi, serta nilai penting (INP) yang cenderung tinggi di berbagai ketinggian tempat. Hal ini menunjukkan bahwa Lasa (Castanopsis buruana Miq) mendominasi areal tempat tumbuh, dan mempunyai penguasaan lahan yang cukup besar jika dibandingkan dengan jenis lainnya. Perbandingan nilai penting (INP) Lasa (Castanopsis buruana Miq) dengan jenis lainnya dapat dilihat pada Tabel 1 berikut.

Tabel 1. Perbandingan Nilai Penting (INP) Lasa (Castanopsis buruana Miq) dengan jenis lainnya di lokasi penelitian

\begin{tabular}{|c|c|c|c|}
\hline $\begin{array}{c}\text { Lokasi } \\
\text { (Tinggi Tempat) } \\
\end{array}$ & $\begin{array}{c}\text { Tingkat } \\
\text { Pertumbuhan }\end{array}$ & Jenis & INP \\
\hline \multirow{19}{*}{$\begin{array}{l}\text { Desa Hunitetu } \\
\text { (300 mdpl) }\end{array}$} & \multirow[t]{4}{*}{ Semai } & Castanopsis buruana Miq & 100,00 \\
\hline & & Macaranga sp & 50,00 \\
\hline & & Alstonia scholaris & 25,00 \\
\hline & & Timonius timon Merr & 25,00 \\
\hline & \multirow[t]{5}{*}{ Sapihan } & Castanopsis buruana Miq & 85,71 \\
\hline & & Macaranga sp & 28,57 \\
\hline & & Alstonia scholaris & 28,57 \\
\hline & & Pometia pinnata & 28,57 \\
\hline & & Timonius timon Merr & 28,57 \\
\hline & \multirow[t]{4}{*}{ Tiang } & Vitex cofassus & 48,963 \\
\hline & & Castanopsis buruana Miq & 154,94 \\
\hline & & Macaranga sp & 44,817 \\
\hline & & Pometia pinnata & 51,276 \\
\hline & \multirow[t]{6}{*}{ Pohon } & Acacia mangium Willd & 12,966 \\
\hline & & Vitex cofassus & 26,71 \\
\hline & & Castanopsis buruana Miq & 187,14 \\
\hline & & Macaranga sp & 12,76 \\
\hline & & Alstonia scholaris & 20,48 \\
\hline & & Pometia pinnata & 39,93 \\
\hline \multirow{8}{*}{$\begin{array}{l}\text { Desa Hunitetu } \\
\text { (400 mdpl) }\end{array}$} & \multirow[t]{6}{*}{ Semai } & Eugenia $\mathrm{sp}$ & 12,45 \\
\hline & & Dryobalanops aromatica & 24,90 \\
\hline & & Castanopsis buruana Miq & 37,60 \\
\hline & & Macaranga sp & 46,88 \\
\hline & & Metrosideros vera Roxb & 78,14 \\
\hline & & Timonius timon Merr & 9,27 \\
\hline & \multirow[t]{2}{*}{ Sapihan } & Vitex cofassus & 33,33 \\
\hline & & Eugenia $\mathrm{sp}$ & 66,66 \\
\hline
\end{tabular}


Lanjutan Tabel 1.

\begin{tabular}{|c|c|c|c|}
\hline $\begin{array}{l}\text { Lokasi (Tinggi } \\
\text { Tempat) }\end{array}$ & $\begin{array}{c}\text { Tingkat } \\
\text { pertumbuhan }\end{array}$ & Jenis & INP \\
\hline & & Castanopsis buruana Miq & 66,66 \\
\hline & & Macaranga $s p$ & 33,33 \\
\hline & Tiang & Eugenia sp & 29,52 \\
\hline & & Dryobalanops aromatica & 28,25 \\
\hline & & Castanopsis buruana Miq & 194,09 \\
\hline & & Metrosideros vera Roxb & 48,13 \\
\hline & Pohon & Eugenia sp & 14,37 \\
\hline & & Dryobalanops aromatica & 29,02 \\
\hline & & Castanopsis buruana Miq & 197,41 \\
\hline & & Artocarpus sp & 14,37 \\
\hline & & Metrosideros vera Roxb & 44,81 \\
\hline \multirow{16}{*}{$\begin{array}{l}\text { Desa Hunitetu } \\
\text { (500 mdpl) }\end{array}$} & \multirow[t]{3}{*}{ Semai } & Castanopsis buruana Miq & 100,00 \\
\hline & & Macaranga $s p$ & 75,00 \\
\hline & & Alstonia scholaris & 25,00 \\
\hline & \multirow[t]{5}{*}{ Sapihan } & Dryobalanops aromatica & 14,23 \\
\hline & & Castanopsis buruana Miq & 127,43 \\
\hline & & Macaranga $s p$ & 26,73 \\
\hline & & Alstonia scholaris & 17,36 \\
\hline & & Timonius timon Merr & 14,23 \\
\hline & \multirow{3}{*}{ Tiang } & Castanopsis buruana Miq & 195,65 \\
\hline & & Macaranga $s p$ & 70,99 \\
\hline & & Alstonia scholaris & 33,35 \\
\hline & \multirow[t]{5}{*}{ Pohon } & Dryobalanops aromatica & 13,44 \\
\hline & & Castanopsis buruana Miq & 203,13 \\
\hline & & Macaranga $s p$ & 27,14 \\
\hline & & Alstonia scholaris & 22,21 \\
\hline & & Paraserianthes falcataria & 34,06 \\
\hline \multirow{22}{*}{$\begin{array}{l}\text { Desa Murnaten } \\
\quad(300 \mathrm{mdpl})\end{array}$} & \multirow[t]{7}{*}{ Semai } & Vitex cofassus & 55,55 \\
\hline & & Castanopsis buruana Miq & 47,22 \\
\hline & & Elaeocarpus sp & 19,44 \\
\hline & & Shorea selanica $\mathrm{BL}$ & 19,44 \\
\hline & & Calophyllum inophyllum & 19,44 \\
\hline & & Durio zibethinus & 19,44 \\
\hline & & Anthocephalus macrophyllus & 19,44 \\
\hline & \multirow[t]{7}{*}{ Sapihan } & Castanopsis buruana Miq & 74,64 \\
\hline & & Lansium parasiticum & 33,97 \\
\hline & & Diospyros $s p$ & 28,70 \\
\hline & & Shorea selanica $\mathrm{BL}$ & 14,35 \\
\hline & & Anthocephalus macrophyllus & 19,61 \\
\hline & & Eusideroxylon zwageri & 14,35 \\
\hline & & Cananga odorata & 14,35 \\
\hline & \multirow[t]{8}{*}{ Tiang } & Miristica lepidla & 26,28 \\
\hline & & Calophyllum inophyllum & 22,14 \\
\hline & & Eugenia aromatica & 31,59 \\
\hline & & Castanopsis buruana Miq & 117,34 \\
\hline & & Shorea selanica $\mathrm{BL}$ & 19,18 \\
\hline & & Mallotus philippensis Muel.Arg & 22,95 \\
\hline & & Agathis alba & 24,60 \\
\hline & & Eusideroxylon zwageri & 17,23 \\
\hline
\end{tabular}


Lanjutan Tabel 1.

\begin{tabular}{|c|c|c|c|}
\hline $\begin{array}{l}\text { Lokasi (Tinggi } \\
\text { Tempat) }\end{array}$ & $\begin{array}{c}\text { Tingkat } \\
\text { pertumbuhan }\end{array}$ & Jenis & INP \\
\hline & & Anthocephalus macrophyllus & 18,65 \\
\hline & Pohon & Eugenia aromatica & 9,99 \\
\hline & & Agathis alba & 11,55 \\
\hline & & Castanopsis buruana Miq & 142,92 \\
\hline & & Eugenia sp & 11,30 \\
\hline & & Anthocephalus macrophyllus & 42,50 \\
\hline & & Ficus variegata & 11,43 \\
\hline & & Shorea selanica $B L$ & 9,27 \\
\hline & & Intsia bijuga & 9,86 \\
\hline & & Durio zibethinus & 22,45 \\
\hline & & Nephelium lappaceum & 9,24 \\
\hline & & Vitex cofassus & 9,57 \\
\hline & & Diospyros $\mathrm{sp}$ & 9,88 \\
\hline \multirow{33}{*}{$\begin{array}{l}\text { Desa Murnaten } \\
(400 \mathrm{mdpl})\end{array}$} & \multirow[t]{6}{*}{ Semai } & Anthocephalus macrophyllus & 28,57 \\
\hline & & Castanopsis buruana Miq & 57,14 \\
\hline & & Pometia pinnata & 28,57 \\
\hline & & Agathis alba & 28,57 \\
\hline & & Calophyllum inophyllum & 28,57 \\
\hline & & Vitex cofassus & 28,57 \\
\hline & \multirow[t]{6}{*}{ Sapihan } & Lansium domesticum & 17,00 \\
\hline & & Anthocephalus macrophyllus & 34,28 \\
\hline & & Eugenia aromatica & 41,42 \\
\hline & & Agathis alba & 17,14 \\
\hline & & Castanopsis buruana Miq & 72,85 \\
\hline & & Shorea selanica $\mathrm{BL}$ & 17,14 \\
\hline & \multirow[t]{8}{*}{ Tiang } & Diospyros $\mathrm{sp}$ & 25,55 \\
\hline & & Castanopsis buruana Miq & 134,59 \\
\hline & & Eusideroxylon zwageri & 21,82 \\
\hline & & Shorea selanica $\mathrm{BL}$ & 23,23 \\
\hline & & Anthocephalus macrophyllus & 19,78 \\
\hline & & Elaeocarpus $s p$ & 29,88 \\
\hline & & Calophyllum inophyllum & 22,84 \\
\hline & & Eugenia aromatica & 22,27 \\
\hline & \multirow[t]{13}{*}{ Pohon } & Litsea angulata & 8,56 \\
\hline & & Diospyros $\mathrm{sp}$ & 8,78 \\
\hline & & Shorea selanica $B L$ & 20,42 \\
\hline & & Miristica lepidla & 8,54 \\
\hline & & Eugenia aromatica & 17,68 \\
\hline & & Elaeocarpus $s p$ & 8,89 \\
\hline & & Castanopsis buruana Miq & 158,16 \\
\hline & & Eusideroxylon zwageri & 9,55 \\
\hline & & Anthocephalus macrophyllus & 22,76 \\
\hline & & Pometia pinnata & 9,20 \\
\hline & & Agathis alba & 8,89 \\
\hline & & Vitex cofassus & 9,73 \\
\hline & & Eugenia $\mathrm{sp}$ & 8,77 \\
\hline \multirow{6}{*}{$\begin{array}{l}\text { Desa Murnaten } \\
\text { (500 mdpl) }\end{array}$} & \multirow[t]{6}{*}{ Semai } & Terminalia cattapa & 26,78 \\
\hline & & Anthocephalus macrophyllus & 39,28 \\
\hline & & Castanopsis buruana Miq & 53,57 \\
\hline & & Eugenia aromatica & 26,78 \\
\hline & & Gmelina moluccana & 26,78 \\
\hline & & Elaeocarpus $s p$ & 26,78 \\
\hline
\end{tabular}


Lanjutan Tabel 1.

\begin{tabular}{|c|c|c|c|}
\hline $\begin{array}{c}\text { Lokasi (Tinggi } \\
\text { Tempat) }\end{array}$ & $\begin{array}{c}\text { Tingkat } \\
\text { pertumbuhan }\end{array}$ & Jenis & INP \\
\hline & \multirow[t]{7}{*}{ Sapihan } & Terminalia cattapa & 13,94 \\
\hline & & Elaeocarpus sp & 13,94 \\
\hline & & Durio zibethinus & 13,94 \\
\hline & & Miristica lepidla & 13,94 \\
\hline & & Castanopsis buruana Miq & 102,40 \\
\hline & & Eugenia aromatica & 13,94 \\
\hline & & Anthocephalus macrophyllus & 27,88 \\
\hline & \multirow[t]{7}{*}{ Tiang } & Lansium domesticum & 17,61 \\
\hline & & Eugenia aromatica & 56,42 \\
\hline & & Castanopsis buruana Miq & 149,12 \\
\hline & & Anthocephalus macrophyllus & 38,88 \\
\hline & & Eusideroxylon zwageri & 20,85 \\
\hline & & Elaeocarpus $s p$ & 17,09 \\
\hline & & Shorea selanica $B L$ & 16,61 \\
\hline \multirow{12}{*}{$\begin{array}{c}\text { Desa Murnaten } \\
(500 \mathrm{mdpl})\end{array}$} & \multirow[t]{12}{*}{ Pohon } & Anthocephalus macrophyllus & 21,083 \\
\hline & & Gmelina moluccana & 10,268 \\
\hline & & Ficus benjamina & 11,983 \\
\hline & & Castanopsis buruana Miq & 153,91 \\
\hline & & Terminalia catappa & 9,5451 \\
\hline & & Elaeocarpus $s p$ & 10,145 \\
\hline & & Eusideroxylon zwageri & 10,896 \\
\hline & & Durio zibethinus & 17,559 \\
\hline & & Eugenia aromatica & 20,47 \\
\hline & & Artocarpus communis & 12,314 \\
\hline & & Diospyros sp & 9,6349 \\
\hline & & Paraserianthes falcataria & 12,196 \\
\hline
\end{tabular}

Dari tabel di atas menunjukkan bahwa untuk lokasi Desa Hunitetu, nilai penting Lasa pada tingkatan semai pada ketinggian $300 \mathrm{~m}$ dpl mencapai 50\%; ketinggian $400 \mathrm{~m}$ dpl mencapai 19,97\%; dan ketinggian $500 \mathrm{~m}$ dpl mencapai $50 \%$. Nilai penting lasa pada tingkatan sapihan pada ketinggian 300 m dpl mencapai 42,86\%; ketinggian $400 \mathrm{~m}$ dpl mencapai 33,33\%; dan ketinggian $500 \mathrm{~m}$ dpl mencapai $63,72 \%$. Nilai penting lasa pada tingkatan tiang pada ketinggian $300 \mathrm{~m}$ dpl mencapai 51,65\%; ketinggian 400

m dpl mencapai 64,70\%; dan ketinggian $500 \mathrm{~m}$ dpl mencapai $65,22 \%$. Nilai penting lasa pada tingkatan pohon pada ketinggian 300 m dpl mencapai 62,38\%; ketinggian 400 m dpl mencapai 65,80\%; dan ketinggian $500 \mathrm{~m} \quad \mathrm{dpl}$ mencapai $67,71 \%$.

Lokasi Desa Murnaten, nilai penting lasa pada tingkatan semai pada ketinggian $300 \quad \mathrm{~m}$ dpl mencapai 23,61\%; ketinggian $400 \mathrm{~m} \quad \mathrm{dpl}$ 
mencapai 28,57\%; dan ketinggian 500 m dpl mencapai $26,79 \%$. Nilai penting lasa pada tingkatan sapihan pada ketinggian $300 \mathrm{~m}$ dpl mencapai 74,64\%; ketinggian $400 \quad \mathrm{~m} \quad \mathrm{dpl}$ mencapai 36,43\%; dan ketinggian 500 m dpl mencapai $51,20 \%$. Nilai penting lasa pada tingkatan tiang pada ketinggian $300 \quad \mathrm{~m} \quad \mathrm{dpl}$ mencapai 39,11\%; ketinggian $400 \quad \mathrm{~m} \quad \mathrm{dpl}$ mencapai 44,86\%; dan ketinggian 500 m dpl mencapai $47,10 \%$. Nilai penting lasa pada tingkatan pohon pada ketinggian $300 \mathrm{~m} \quad \mathrm{dpl}$ mencapai 47,64\%; ketinggian $400 \quad \mathrm{~m} \quad \mathrm{dpl}$ mencapai 52,72\%; dan ketinggian 500 m dpl mencapai 51,30\%.

Kerapatan lasa di lokasi penelitian (Desa Hunitetu dan Desa Murnaten) dapat dilihat pada Tabel 2 berikut ini.

Tabel 2. Nilai Kerapatan Lasa (Castanopsis buruana Miq) di Lokasi Penelitian

\begin{tabular}{|c|c|c|c|c|c|}
\hline No & Lokasi & $\begin{array}{c}\text { Kerapatan } \\
\text { (Individu/Ha) }\end{array}$ & No & Lokasi & $\begin{array}{c}\text { Kerapatan } \\
\text { (Individu/Ha) }\end{array}$ \\
\hline \multirow[t]{16}{*}{1.} & \multicolumn{2}{|l|}{ Desa Hunitetu } & \multirow[t]{16}{*}{2.} & \multicolumn{2}{|l|}{ Desa Murnaten } \\
\hline & \multicolumn{2}{|c|}{ Ketinggian $300 \mathrm{~m} \mathrm{dpl}$} & & \multicolumn{2}{|c|}{ Ketinggian $300 \mathrm{~m} \mathrm{dpl}$} \\
\hline & - Semai & 2.000 & & - Semai & 1.000 \\
\hline & - Sapihan & 240 & & - Sapihan & 720 \\
\hline & - Tiang & 60 & & - Tiang & 200 \\
\hline & - Pohon & 120 & & - Pohon & 105 \\
\hline & \multicolumn{2}{|c|}{ Ketinggian $400 \mathrm{~m} \mathrm{dpl}$} & & \multicolumn{2}{|c|}{ Ketinggian $400 \mathrm{~m} \mathrm{dpl}$} \\
\hline & - Semai & 7.000 & & - Semai & 1.000 \\
\hline & - Sapihan & 160 & & - Sapihan & 480 \\
\hline & - Tiang & 140 & & - Tiang & 180 \\
\hline & - Pohon & 135 & & - Pohon & 130 \\
\hline & \multicolumn{2}{|c|}{ Ketinggian $500 \mathrm{~m} \mathrm{dpl}$} & & \multicolumn{2}{|c|}{ Ketinggian $500 \mathrm{~m} \mathrm{dpl}$} \\
\hline & - Semai & 2.000 & & - Semai & 1.000 \\
\hline & - Sapihan & 1.840 & & - Sapihan & 720 \\
\hline & - Tiang & 120 & & - Tiang & 220 \\
\hline & - Pohon & 130 & & - Pohon & 135 \\
\hline
\end{tabular}

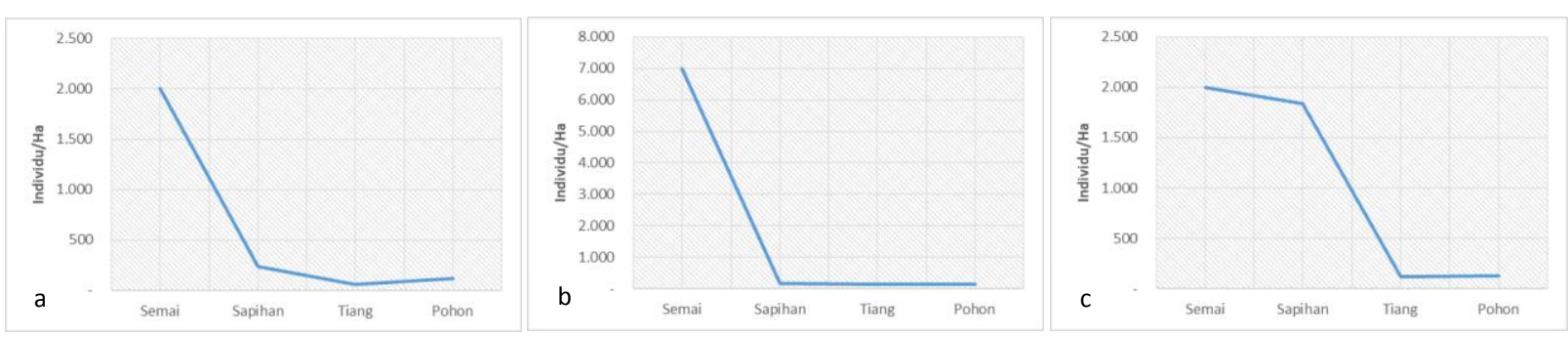

Gambar 3. Struktur Populasi Lasa (Castanopsis buruana Miq) di Desa Hunitetu berdasarkan ketinggian tempat. (a) ketinggian $300 \mathrm{~m}$ dpl, (b) ketinggian $400 \mathrm{~m}$ dpl, dan (c) ketinggian $500 \mathrm{~m}$ dpl. 


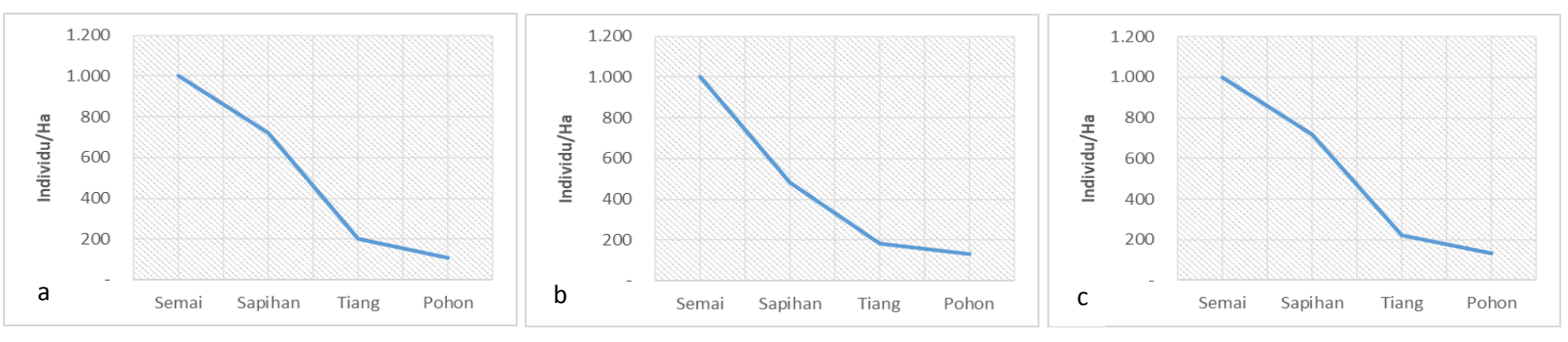

Gambar 4. Struktur Populasi Lasa (Castanopsis buruana Miq) di Desa Murnaten berdasarkan ketinggian tempat. (a) ketinggian $300 \mathrm{~m}$ dpl, (b) ketinggian $400 \mathrm{~m}$ dpl, dan (c) ketinggian $500 \mathrm{~m}$ dpl.

$\begin{array}{llll}\text { Struktur populasi } & \text { Lasa } & & \text { pertumbuhan atau tingkat permudaan, } \\ \text { (Castanopsis buruana Miq) } & \text { yang } & \text { khususnya yang berkaitan dengan } \\ \text { ditemukan baik di Desa Hunitetu dan } & \text { regenerasi populasi. Hal ini } \\ \text { Desa Murnaten membentuk struktur } & \text { mengindikasikan potensi } & \text { Lasa } \\ \text { populasi dengan bentuk kurva "J" } & \text { (Castanopsis buruana Miq) dalam } \\ \text { terbalik atau dapat disebut juga dengan } & \text { jangka panjang sebagai bahan pangan } \\ \text { struktur populasi muda, dimana } & \text { alternatif pada kedua lokasi tergolong } \\ \text { populasi memiliki jumlah individu } & \text { sangat baik. }\end{array}$
paling banyak pada tingkatan semai, kemudian semakin berkurang pada tingkatan sapihan, tiang, dan pohon. Atau dengan kata lain, struktur ini dicirikan dengan pertumbuhan yang banyak pada fase pre-reproduktif pertumbuhan sedang pada fase reproduktif - dan pertumbuhan rendah pada fase post-reproduktif. Kondisi struktur populasi demikian diperkirakan mampu untuk mempertahankan keberadaan populasi dalam jangka panjang karena memiliki individu-individu di setiap fase

Sedangkan berdasarkan sebaran kelas diameter, potensi lasa tertinggi di Desa Hunitetu umumnya tersebar pada kelas diameter 20-29 cm, 30-39 cm, 40-49 cm, dan 50-59 cm dengan kerapatan pohon berturut-turut adalah 10 pohon/ha, 70 pohon/ha, 30 pohon/ha, dan 10 pohon/ha. Sedangkan untuk Desa Murnaten umumnya tersebar pada kelas diameter 20-29 cm, 30-39 cm, dan 40-49 cm dengan kerapatan pohon berturut-turut adalah 20 pohon/ha, 65 pohon/ha, dan 35 pohon/ha. 

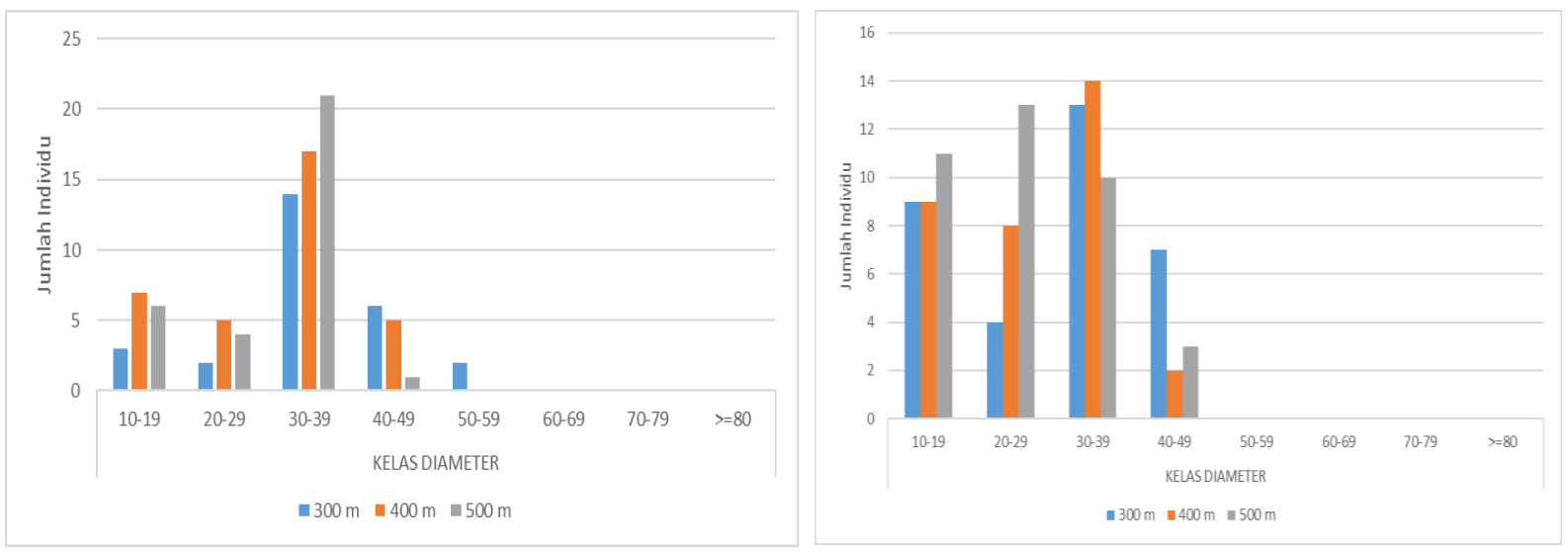
Gambar 5. Potensi Lasa (Castanopsis buruana Miq) berdasarkan Kelas Diameter
di Desa Hunitetu (kiri) dan Desa Murnaten (kanan)

Pola Sebaran Lasa (Castanopsis buruana Miq)

Penelitian

lapangan

menunjukkan bahwa ketinggian tempat tumbuh berpengaruh terhadap sebaran Lasa di alam. Hal ini terlihat dari hasil penelitian yang menunjukkan bahwa Lasa tidak ditemukan pada hutan pantai sampai dengan hutan dataran rendah dengan ketinggian tempat kurang dari 300 meter dari permukaan laut untuk semua lokasi penelitian, baik itu Desa Hatusua, Hunitetu maupun Desa Murnaten. Lasa (Castanopsis buruana Miq) baru akan ditemukan pada daerah dengan ketinggian di atas $300 \mathrm{~m}$ dari permukaan laut pada hutan dataran rendah dan dapat tumbuh terus sampai pada hutan pegunungan. Hal ini berarti bahwa secara alami, lasa tidak dapat beradaptasi dengan habitat pada ketinggian $<300 \mathrm{~m}$ dpl.

Hasil perhitungan Indeks Morisita menunjukkan bahwa pola sebaran Lasa (Castanopsis buruana Miq) di Kabupaten Seram Bagian Barat memiliki pola sebaran mengelompok (clumped). Pola sebaran mengelompok dapat mencerminkan habitat yang heterogen dan metode reproduksi dari Lasa secara alami di alam.

\section{Lasa (Castanopsis buruana} Miq) memiliki preferensi habitat pada daerah-daerah yang terbuka dan umumnya toleran terhadap sinar matahari penuh. Untuk itu jika musim berbunga semua tangkai mengeluarkan bunga, karena proses pembungaan sangat dipengaruhi oleh sinar matahari. 
Tabel 3. Indeks Morisita Terstandar untuk lokasi Desa Hunitetu

\begin{tabular}{|c|c|c|c|}
\hline \multirow{2}{*}{$\begin{array}{c}\text { Ketinggian tempat } \\
\text { dari permukaan laut } \\
(\mathbf{m} \text { dpl) }\end{array}$} & \multicolumn{3}{|c|}{ Indeks Morisita } \\
\cline { 2 - 4 } & $\mathbf{I p}$ & Kriteria & Pola Sebaran \\
\hline $300 \mathrm{~m}$ & 0,060489 & $\mathrm{I}_{\mathrm{p}}>0$ & Mengelompok \\
\hline $400 \mathrm{~m}$ & 0,088912 & $\mathrm{I}_{\mathrm{p}}>0$ & Mengelompok \\
\hline $500 \mathrm{~m}$ & 0,081867 & $\mathrm{I}_{\mathrm{p}}>0$ & Mengelompok \\
\hline
\end{tabular}

Tabel 4. Indeks Morisita Terstandar untuk lokasi Desa Murnaten

\begin{tabular}{|c|c|c|c|}
\hline $\begin{array}{c}\text { Ketinggian tempat } \\
\text { dari permukaan laut } \\
(\mathbf{m} \text { dpl) }\end{array}$ & \multicolumn{3}{|c|}{ Indeks Morisita } \\
\cline { 2 - 4 } & Ip & Kriteria & Pola Sebaran \\
\hline $300 \mathrm{~m}$ & 0,120282695 & $\mathrm{I}_{\mathrm{p}}>0$ & Mengelompok \\
\hline $400 \mathrm{~m}$ & 0,089832007 & $\mathrm{I}_{\mathrm{p}}>0$ & Mengelompok \\
\hline $500 \mathrm{~m}$ & 0,241905269 & $\mathrm{I}_{\mathrm{p}}>0$ & Mengelompok \\
\hline
\end{tabular}
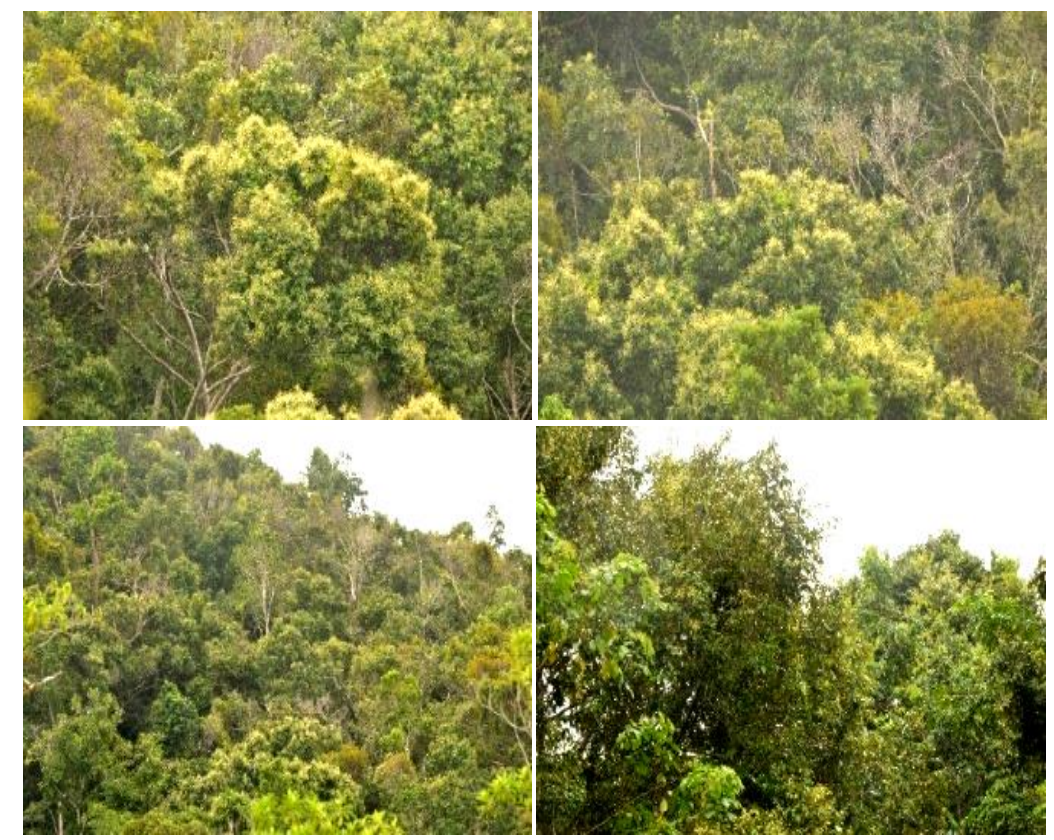

Gambar 6. Kondisi Tegakan Lasa (Castanopsis buruana Miq) di Desa Hunitetu 


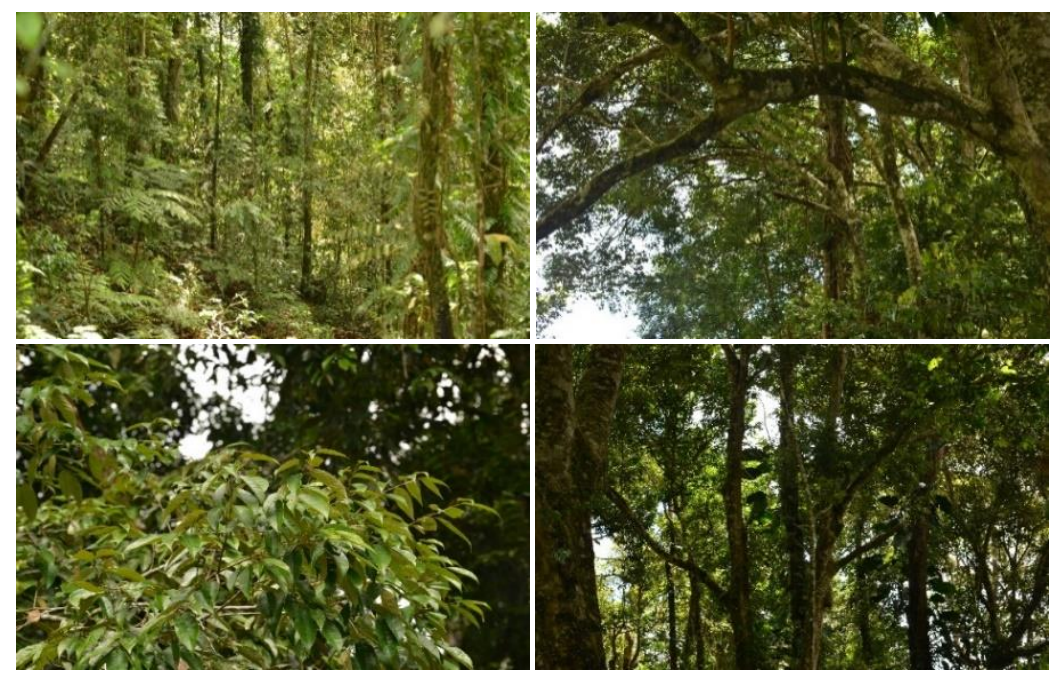

Gambar 7. Kondisi Tegakan Lasa (Castanopsis buruana Miq) di Desa Murnate

\section{Pemanfaatan Lasa oleh Masyarakat}

Castanopsis buruana Miq yang

oleh orang Maluku (Pulau Seram) disebut dengan nama Lasa atau pohon Lasa merupakan tanaman hutan yang tumbuh pada tanah-tanah yang miskin unsur hara yang berada pada ketinggian $500 \mathrm{~m}$ dari permukaan laut. Menurut masyarakat Pohon Lasa (Castanopsis buruana Miq) biasanya berbuah pada bulan Agustus sampai dengan September.

Hasil penelitian yang dilakukan di tiga Desa di Kabupaten Seram Bagian Barat (SBB), yaitu Desa Hatusua, Desa Hunitetu dan Desa Murnaten, berdasarkan hasil wawancara dengan masyarakat yang hanya memanfaatkan pohon Lasa sebagai bahan pangan adalah Desa Hunitetu. Sedangkan Desa Hatusua dan Desa Murnaten hanya mengetahui saja kalau pohon ini dapat dimakan tapi tidak mengkonsumsinya saat musim berbuah.

Semua jenis Castanopsis dapat dimakan dan digunakan saat kekurangan makanan, atau ketika makanan yang lebih berkualitas tidak tersedia. Biji biasanya dimasak sebelum dimakan, meskipun juga bisa dimakan mentah. Biji bisa dimakan utuh, tetapi biasanya dikeringkan, kemudian ditumbuk menjadi bubuk dan digunakan sebagai pengental dalam rebusan dll atau dicampur dengan sereal untuk membuat roti. Masalah utama dari biji adalah sering mengandung tanin, membuatnya pahit dan sepat. Tanin ini sebagian besar dapat dihilangkan dengan merendam benih dalam air 
kemudian membuang air. Proses ini harus diulang sampai benih tidak lagi terasa pahit (Fern, K. 2018).

Berdasarkan hasil wawancara dengan masyarakat di Desa Hunitetu, biji dari buah lasa ini biasanya dimakan sebagai cemilan dan snack tetapi juga sebagai pengganti beras yaitu (dimasak dengan air sebagai nasi) juga dimasak dengan santan sebagai bubur. Bentuk pengolahannya juga berbeda, kalau sebagai cemilan dan snack
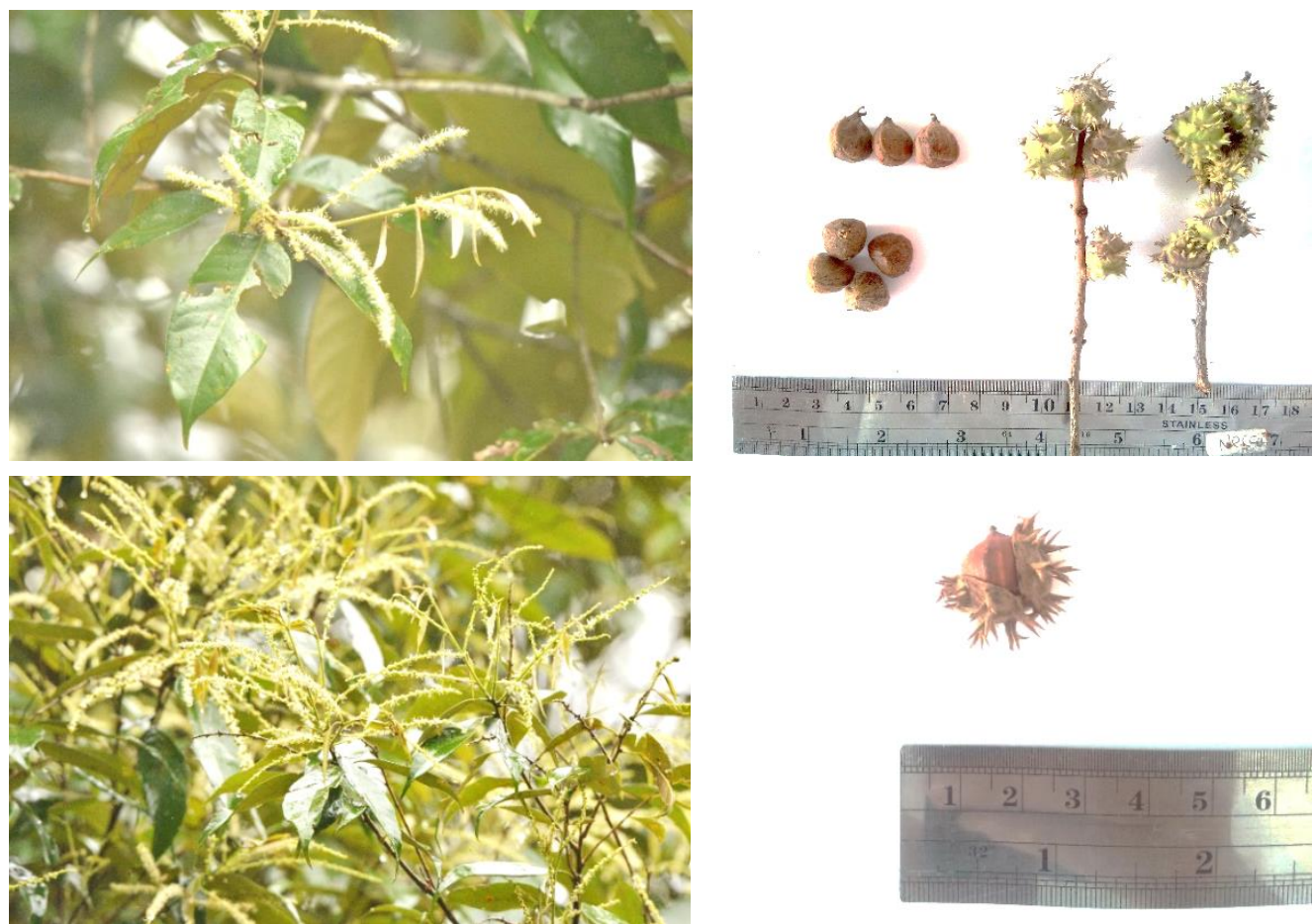

Sumber : data primer, 2017 pengolahannya yaitu digoreng dengan pasir dengan perbandingan 1:1 (pasir : biji lasa), sampai bijinya matang, setelah itu baru dikupas kulitnya baru dimakan. Bentuk pengelolaan sebagai pengganti beras yaitu dengan cara bijinya dijemur sampai kering baru ditumbuk untuk menghilangkan kulitnya setelah itu baru masak sebagai nasi maupun bubur.

Gambar 8. Buah, Bunga dan Biji Lasa (Castanopsis buruana Miq) 


\section{KESIMPULAN}

Potensi pohon Lasa

(Castanopsis buruana Miq) di Desa Hunitetu untuk ketinggian 300-500 m dpl berturut-turut sebesar 120 pohon/ha, 135 pohon/ha, dan 130 pohon/ha. Sedangkan potensi pohon lasa di Desa Murnaten untuk ketinggian 300-500 m dpl berturut-turut sebesar 105 pohon/ha, 130 pohon/ha, dan 135 pohon/ha.

Struktur populasi Lasa (Castanopsis buruana Miq) yang ditemukan baik di Desa Hunitetu dan Desa Murnaten membentuk struktur populasi dengan bentuk kurva "J" terbalik atau dapat disebut juga dengan struktur populasi muda, dimana populasi memiliki jumlah individu paling banyak pada tingkatan semai, kemudian semakin berkurang pada tingkatan sapihan, tiang, dan pohon.

Indeks Morisita menunjukkan bahwa pola sebaran Lasa (Castanopsis buruana Miq) di Kabupaten Seram Bagian Barat memiliki pola sebaran mengelompok (clumped). Pola sebaran mengelompok dapat mencerminkan habitat yang heterogen dan metode reproduksi dari lasa secara alami di alam. Masyarakat di Desa Hunitetu umumnya memanfaatkan biji dari buah lasa ini untuk dimakan sebagai cemilan dan snack tetapi juga sebagai pengganti beras yaitu (dimasak dengan air sebagai nasi) juga dimasak dengan santan sebagai bubur.

\section{UCAPAN TERIMA KASIH}

Terima Kasih kepada Bapak Rektor UNPATTI, Ketua LPPM UNPATTI dan Dekan Fakultas Pertanian UNPATTI yang telah menfasilitasi penelitian ini. Penelitian ini dibiayai dengan Dana PNBP Sesuai SK Rektor Universitas Pattimura Nomor : 588/UN.13/SK/2017

\section{DAFTAR PUSTAKA}

Fern, K. 2018. Castanopsis buruana Miq. Fagaceae. Tropical Plants Database, http://tropical.theferns.info/viewtr opical. php?id=Castanopsis+buruana. Diakses tanggal 15 September 2018.

Kusumasari, B., 2015. Perubahan Iklim dan Strategi Adaptasi di Indonesia. Jurnal, 4(3), pp.2-15.

Morisita, M. 1959. Measuring of the dispersion of individuals and analysis of the distributional patterns. Mem. Fac. Sci. Kyushu Univ. Ser. E, 2(21), 5-23.

Mueller-Dombois, D. and H. Ellenberg, 1974, Aims and Methods of Vegetation Ecology, John Wiley $\&$ Sons, New York.

Perdana, T.A. and Susilowati, I., 2015. Dampak Perubahan Iklim 
Terhadap Nelayan Tangkap (Studi Empiris di Pesisir Utara Kota Semarang) (Doctoral dissertation, Fakultas Ekonomika dan Bisnis).
Puspitojati, T., Rachman, E., Ginoga, K.L. and Darusman, D., 2014. Hutan Tanaman Pangan: Realitas, Konsep, dan Pengembangan. Penerbit PT Kanisius. 